\title{
A Dynamic Method for Determining the Vapor Pressure of Carbon Dioxide at $0{ }^{\circ} \mathrm{C}$
}

\author{
J. L. Edwards* and D. P. Johnson \\ Institute for Basic Standards, National Bureau of Standards, Washington, D.C. 20234 \\ (October 23, 1967)
}

\begin{abstract}
The vapor pressure of carbon dioxide at $0{ }^{\circ} \mathrm{C}$, or at $0.01{ }^{\circ} \mathrm{C}$, has been used as a fixed point on the pressure scale. Comparisons between laboratories may be affected equally by pressure measurements, temperature measurements, and the purity (and possibly isotope composition) of the sample. A dynamic method for establishing this pressure is described, utilizing a device similar to those used to realize the sulfur and steam points on the International Practical Temperature Scale. Advantages of the method include rapid establishment of equilibrium conditions, and the automatic purification of the carbon dioxide. Results obtained indicate a sample-to-sample reproducibility better than one part in 25,000. The method is suggested as being suitable for general use in realizing the $\mathrm{CO}_{2}$ point of the pressure scale. This experiment yielded a value for the vapor pressure at $0^{\circ} \mathrm{C}$ of $3.48516 \mathrm{MN} \mathrm{m}^{-2}$ or $26,140.8 \mathrm{~mm} \mathrm{Hg}$; at the triple point of water, $0.01{ }^{\circ} \mathrm{C}$, it was $3.48608 \mathrm{MN} \mathrm{m}^{-2}$ or $26,147.7 \mathrm{~mm} \mathrm{H}^{\circ}$.
\end{abstract}

Key Words: Carbon dioxide, fixed point, hypsometer, pressure standard, purification, vapor pressure.

\section{Introduction}

The use of fixed points in pressure calibration work, besides having possible direct application in measurement problems, also provides a valuable check on the stability of the pressure scale as determined by piston gages or mercury manometers. One such fixed point is the vapor pressure of carbon dioxide at $0{ }^{\circ} \mathrm{C}$. Six careful determinations of the " $\mathrm{CO}_{2}$ point" have been made in the last forty years $[1,2,3,4,5,6]^{1}$. All of these determinations used a static method in which a pressure vessel containing purified $\mathrm{CO}_{2}$ was placed in a cryostat of known temperature. The pressure was then measured when the vapor-liquid mixture reached an equilibrium pressure. The results of these six determinations, given later in table 3 , show a scatter with a range of about 5 parts in 10,000 . The precision of the individual investigations, however, was in each case reported to be 1 part in 10,000 or better. This seems to indicate that the static method is subject to systematic errors which can go undetected even in very careful work. The static method of measuring vapor pressure faces several problems: While the experimenter may use elaborate procedures to obtain pure $\mathrm{CO}_{2}$, the samples may be contaminated after filling the pressure vessel, as by leaching materials from the walls. It is difficult to eliminate temperature

\footnotetext{
*Work done in partial fulfillment of requirement for a degree of Mister of Science ${ }^{*}$ Work done in partial fulfillment of requirement for a degree of Master of Scien
George Washington University. Present address: 5709 Gross Dr., Dayton, Ohio 45431.

' Figures in brackets indicate the literature references at the end of this paper.
}

gradients between the bath, the thermometer, and the interface between the liquid and vapor phases. A microscopic real or virtual leak, as by temperature fluctuations in the portions of the sample in parts of the apparatus outside the bath, will shift the temperature of the interface. Such corrections as those for gas head, capillarity and head corrections, in a mercury separator between the $\mathrm{CO}_{2}$ vapor and the fluid used in the piston gage, may contribute susbtantial random and systematic errors. The object of the present work, therefore, is to develop an independent method of making the measurement which is less subject to systematic error. This method is suggested as being suitable for general use in interlaboratory comparisons.

\section{Apparatus for the Dynamic Measurement of the Vapor Pressure of $\mathrm{CO}_{2}$}

\subsection{General}

The apparatus is patterned after the device used to reproduce two fixed points on the International Practical Temperature Scale - the boiling point of water and the boiling point of sulfur, and described in detail by Stimson [7]. It is similar to the "hypsometer" used by physical chemists. A schematic drawing of the $\mathrm{CO}_{2}$ point boiler or hypsometer is shown in figure 1 . In operation, liquid $\mathrm{CO}_{2}$ in the bottom of the hypsometer 


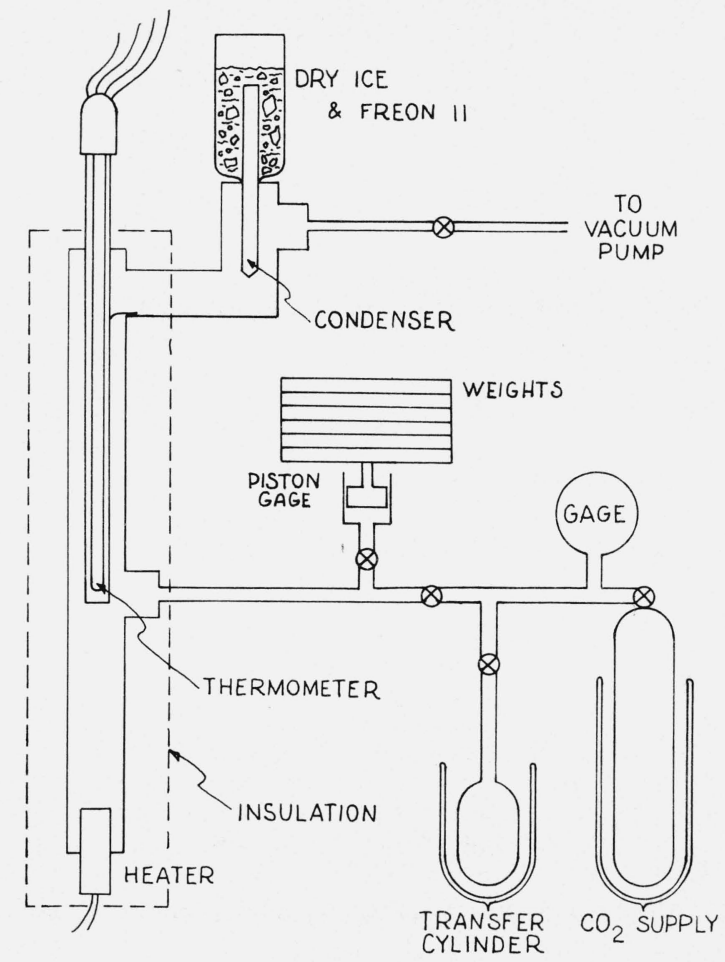

FiguRE 1. Schematic diagram of apparatus.

is heated to the boiling point. The rising $\mathrm{CO}_{2}$ vapor condenses on a "cold finger" and the condensate flows down a thermometer well where the liquid and the vapor come into equilibrium and are in good thermal contact with the thermometer. The pressure at the same level is measured with a gas-lubricated piston gage operating on $\mathrm{CO}_{2}$ directly without the need for the mercury manometer-separator used in the previous determinations.

The advantages of the dynamic method over the static method can be seen at this point. The vaporliquid interface in the hypsometer is relatively large and is being continually renewed. This should allow for an easier attainment of equilibrium. Furthermore, the upward flow of $\mathrm{CO}_{2}$ vapor should tend to concentrate the permanent gas impurities at the top of the hypsometer, and the condensate flowing down the thermometer well should be free of the nonvolatile impurities which remain in the liquid at the bottom of the hypsometer. Since the pressure and temperature are measured at substantially the same level, and the temperature gradient is in a horizontal run of the connecting line, there is no head correction.

\subsection{The Construction of the Hypsometer}

The essential parts of the hypsometer were constructed using l-in stainless steel tubing (type 304, $1 / 32$-in wall thickness) and compression tube fittings. The apparatus was designed with the intention that it should be possible for any reasonably well-equipped laboratory to assemble it from commercially available parts.

The thermometer well was made with $3 / 8$-in stainless steel tubing and was designed to hold a standard platinum-resistance thermometer, 18 inches long. The space surrounding the lower end of the thermometer was filled with liquid (Freon) ${ }^{2}$ to improve thermal contact with the thermometer well. Stainless steel wire, 0.010-in diam, was wound around the lower two-thirds of the well, the turns separated by about one diameter of the wire. This served to slow down the flow of liquid and to provide good thermal contact between the thermometer well and both phases of the $\mathrm{CO}_{2}$. During preliminary studies, the temperature distribution was explored with thermocouples to verify that the thermometer well was out of contact with the walls and that the liquid $\mathrm{CO}_{2}$ from the condenser flowed down the thermometer well.

A brass reentrant plug was machined to fit a compression union. The plug was bored so that a standard $110 \mathrm{~V}, 50 \mathrm{~W}$ soldering element would just fit inside. The space between the interior of the plug and the heater was filled with rosin to hold the heater in position and provide thermal contact. The reentrant part of the heater plug was wound tightly over its full length with type $304,0.010$-in diam, stainless steel wire to trap gas bubbles, thereby preventing superheating of the liquid $\mathrm{CO}_{2}$. A column of about 1 in of packing composed of very small coils of wire was placed between Nichrome screens just above the heater to act as a radiation shield between the heater and the thermometer and to further promote uniform boiling. The packing above the liquid level serves as a short fractionating column.

The condenser consisted of a brass rod, 1/2-in diam, extending about 6 in down into the hypsometer from a reducing union. A polyethylene bottle with its bottom cut off, was fitted on the upper portion of the brass rod. In operation, the condenser was cooled by filling the bottle with a mixture of Freon 11 and dry ice.

The hypsometer, insulated with about two inches of styrofoam, was placed in a 15-gal ice bath. The external connections to the supply cylinders and the piston gage were made with $1 / 4$-in copper tubing and standard flare fittings. The small transfer cylinder shown in figure 1 has a volume of about $1200 \mathrm{ml}$. The volume of the hypsometer itself was calculated to be roughly $400 \mathrm{ml}$.

\subsection{The Temperature and Pressure Measurements}

The platinum-resistance thermometer used was a four-lead thermometer constructed by C. H. Myers. Its resistance was measured with a Mueller temperature bridge. The bridge had been modified by adding a $0.00001 \Omega$ dial and by adding a bridge power supply with provision for variation of the bridge current and

\footnotetext{
${ }^{2}$ Certain commercial products are identified in this paper in order to specify adequately the experimental procedure. In no case does such identification imply recommendation or endorsement by the National Bureau of Standards, nor does it imply that the products or equipment identified are necessarily the best available for the purpose.
} 
for guarding both the power supply and the galvanometer. The bridge balance was determined using a galvanometer-phototube amplifier. The galvanometer had sufficient sensitivity, with a thermometer current of $1 \mathrm{~mA}$, for interpolation to $1 \mu \Omega$ using the 0.00001 $\Omega$ dial, if desired.

The piston gage used in the measurements was one of the two NBS controlled-clearance, air-lubricated piston gages. These piston gages are regarded as primary pressure standards between 1 and 35 atm and are described briefly by Lloyd and Johnson [8]. The controlled-clearance piston gage, in general, is discussed by Johnson and Newhall [9].

A sectional view of the piston gage is shown in figure 2. The piston, 1 in in diameter, is made from Carboloy. The weights used were 50-, 10-, and 1-lb stainless steel weights. Their masses were known to about 1 ppm (part per million). At the pressure of the $\mathrm{CO}_{2}$ point, the sensitivity of the piston gage had been previously observed to be about $1 \mathrm{ppm}$.

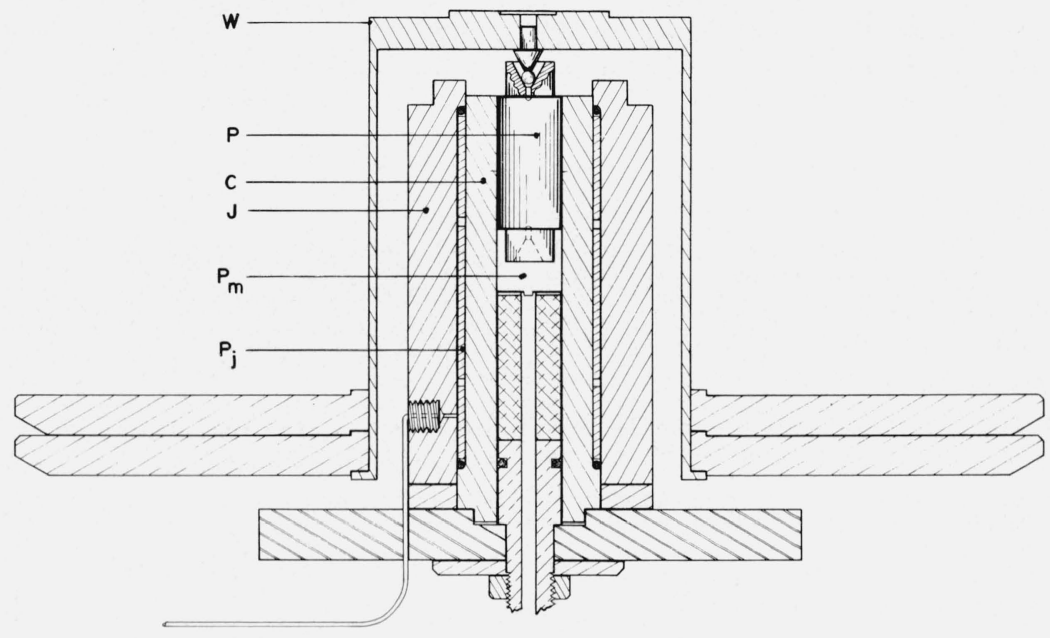

FIGURE 2. Controlled-clearance piston gage.

W. Weights: P. Piston: C, Cylinder: J. Jacket: $P_{m}$. Pressure to be measured: $P_{j}$. Jacket Pressure, adjusted to control clearance between piston and cylinder.

The uncertainties of the measurement are believed not to exceed the following:

\begin{tabular}{|c|c|c|}
\hline & Systematic & Random \\
\hline & \multicolumn{2}{|c|}{ Parts per million } \\
\hline \multirow{2}{*}{\multicolumn{3}{|c|}{$\begin{array}{l}\text { Piston gage parameters } \\
\text { Mass and density of weights }\end{array}$}} \\
\hline & & \\
\hline Piston area & & \\
\hline Elastic deformation & & \\
\hline & 3 & \\
\hline \multirow{2}{*}{\multicolumn{3}{|c|}{$\begin{array}{l}\text { Thermal expansion of piston } \\
\text { Atmospheric pressure }\end{array}$}} \\
\hline & & \\
\hline \multirow{2}{*}{\multicolumn{3}{|c|}{$\begin{array}{l}\text { Air density } \\
\text { Local gravity }\end{array}$}} \\
\hline & & \\
\hline \\
\hline & & 1 \\
\hline Bridge balance & & 5 \\
\hline & & 3 \\
\hline \multicolumn{3}{|l|}{ Measurements with triple-point cell } \\
\hline Realization of triple point & 5 & \\
\hline Bridge balance & & 3 \\
\hline $\begin{array}{l}\text { Change of contact resistance } \\
\text { Total systematic error }\end{array}$ & \\
\hline $\begin{array}{l}\text { Total systematic error } \\
\text { Resultant random error }\end{array}$ & 55 & 8 \\
\hline
\end{tabular}

Here the systematic errors are those which apply to all measurements made with this combination of instruments, and are not reduced by replication of the experiment. The random errors are those which are believed to be independent of each other and of the systematic errors; they are combined as the square root of the sum of the squares. The total uncertainty would be about $56 \mathrm{ppm}$, or about $1.5 \mathrm{~mm} \mathrm{Hg}$.

\section{Experimental Procedure}

\subsection{Purification and Filling}

One of the features desired for a fixed point procedure is that reproducible results be obtainable with material which is readily obtainable, and any necessary purification be done by methods within the resources of the ordinary standards or research laboratory. The pressure to be realized from the fixed point should be insensitive to residual impurities in the range covered by the procedure.

Accordingly commercial carbon dioxide in 20-lb cylinders was used in this experiment. The cylinder of $\mathrm{CO}_{2}$ was set in an insulated container and the lower half cooled with dry ice until the pressure in the cylinder had fallen to the triple point. In the meantime the apparatus, at room temperature, was evacuated to a pressure of about $1 \mathrm{~mm} \mathrm{Hg}$, and then 
rinsed by a flow of gas drawn from the top of the supply cylinder. During this time the supply pressure dropped to just above the atmospheric pressure, so that most of the $\mathrm{CO}_{2}$ was in the solid form. The apparatus was again evacuated. The transfer cylinder was cooled below the temperature of the supply tank, and filled with $\mathrm{CO}_{2}$. About $12 \mathrm{hr}$ were required. Then the transfer cylinder was warmed to room temperature and the apparatus filled to a pressure of about 60 bars. Most of the permanent gas impurities were believed removed from the supply tank and the apparatus during the rinsing.

During the preliminary operations, the apparatus was filled several times, and the carbon dioxide in the supply tank was melted and frozen three times. While a small amount of permanent gas may have been entrapped in the $\mathrm{CO}_{2}$ crystals in the first freezing, this would be released on melting, and removed on the next cycle. By the time the apparatus was filled for the first run, the $\mathrm{CO}_{2}$ must have been quite free of permanent gas impurities. Most of the condensible impurities were retained in the supply cylinder during the sublimation. The content of water vapor, which might be particularly troublesome, is greatly reduced by sublimation, since at $-78{ }^{\circ} \mathrm{C}$ the ratio of the vapor pressure of water to that of carbon dioxide is about 1 to $10^{6}$, as compared with about 1 to 5700 at $0{ }^{\circ} \mathrm{C}$.

\subsection{Vapor Pressure Measurements}

These were performed as follows: Ice was packed into the bath around the hypsometer, dry ice and Freon 11 (monofluoro-trichloromethane, used because it is nontoxic, nonflammable, and does not foam if dry ice is added rapidly) was put into the condenser, and the heater power adjusted until the hypsometer temperature was approximately $0{ }^{\circ} \mathrm{C}$. This power, about $40 \mathrm{~W}$, was such that the $\mathrm{CO}_{2}$ was vaporized at a rate on the order of $1 / 2$ liter per hour. This was sufficient to provide a thin layer of condensed liquid flowing over the entire external surface of the thermometer well. Several hours were allowed to establish a steady state. The piston gage was leveled, and the pressure in the jacket set at the optimum value as determined from the calibration curves of the gage. The weights corresponding to a desired pressure were placed on the piston, and the piston and weight assembly then rotated by hand. The valve connecting the piston and the hypsometer was opened. The heater power was increased slightly until the piston gage lifted and was in a "floating" condition; that is, until the vapor pressure of the $\mathrm{CO}_{2}$ equaled that determined by the piston gage. While the piston gage was floating, the temperature at the bottom of the thermometer well was determined with the platinum resistance thermometer. It was found necessary to make small adjustments in heater power to maintain the piston gage in a floating condition during the 20 to $30 \mathrm{~min}$ required for making a series of normal and reversed readings with the thermometer bridge. By removing a l-lb weight from the piston gage, the above process could be repeated at another pressure.
In this manner, the temperatures corresponding to four different vapor pressures near the ice point were determined.

The other four sets of vapor pressure measurements were made to determine the effect of varying the $\mathrm{CO}_{2}$ flow rate within the hypsometer and to investigate the effect of using unpurified $\mathrm{CO}_{2}$.

For these runs, a fresh cylinder of commerical $\mathrm{CO}_{2}$ was used. This gas had been produced by the decomposition of limestone. The supplier's estimate of the impurity content was as follows:

\begin{tabular}{ll}
\hline \hline Nitrogen & $0.1 \%$ \\
Oxygen & $.03 \%$ \\
Argon & $.001 \%$ \\
Water & $.002 \%$ or less \\
Oil & $.0004 \%$, approx.
\end{tabular}

Runs 2 and 3 were made with gas drawn from this supply cylinder at room temperature with no purification of any kind.

For run 2 the measurements were made at the same flow rate as for run 1 . For run 3 , the area of the cold finger in contact with the cooling mixture was reduced. The heater power, and the flow of liquid were reduced by approximately a factor of ten. The reduced flow was maintained for run 4 but the unpurified $\mathrm{CO}_{2}$ was discarded and the hypsometer refilled with $\mathrm{CO}_{2}$ sublimed from the supply cylinder in the manner described above. Finally, for run 5 the sublimed $\mathrm{CO}_{2}$ was used with the full cooling power and flow rate.

The piston gage temperature and the atmospheric pressure were recorded before and after each vapor pressure measurement, and the platinum-resistance thermometer was calibrated before and after each set of measurements, using a water triple-point cell prepared in the standard manner. The data reduction procedure for the piston gage was that given by Cross [10]. The vapor pressure at $0{ }^{\circ} \mathrm{C}$ was found for each of the five sets of measurements by fitting the pressure to a quadratic equation in the temperature using the OMNITAB least squares solution [11].

\section{Results}

The experimental data are shown in table 1. For each observation the temperature value is the mean of five to ten readings made while the pressure was under the control of the piston gage. The residuals are the deviations of these observations from the smooth quadratic curve.

Two parameters of the quadratic fits for the five runs, i.e., the pressures at $0{ }^{\circ} \mathrm{C}$ and the slopes, are summarized in tables 2 and 3 . In these tables the standard deviations represent the precision of the pressure at $0{ }^{\circ} \mathrm{C}$ for each run, as calculated from the residuals of table 1 .

Table 2 compares the results with three samples of $\mathrm{CO}_{2}$. Run 2, made with gas containing more than 0.13 percent impurities agreed quite closely with runs 1 and 5, made with gas which was relatively pure. 
TABLE 1. The experimental results

\begin{tabular}{r|r|r|r}
\hline \hline $\mathrm{T}\left({ }^{\circ} \mathrm{C}\right)^{*}$ & $\mathrm{P}$ (bars) & $\mathrm{P}(\mathrm{mmHg})$ & \multicolumn{1}{c}{$\begin{array}{c}\text { Residuals } \\
(\mathrm{mmHg})\end{array}$} \\
\hline \multicolumn{3}{|c}{ Run No. 1, sublimed $\mathrm{CO}_{2}$, normal flow } \\
\hline 0.21511 & 35.0515 & 26290.8 & -0.1 \\
.11991 & 34.9633 & 26224.6 & +0.2 \\
.02516 & 34.8751 & 26158.5 & -0.2 \\
-.07146 & 34.7868 & 26092.3 & +0.1 \\
\hline
\end{tabular}

Run No. 2, $\mathrm{CO}_{2}$ not purified, normal flow

\begin{tabular}{r|r|r|r}
0.21422 & 35.0488 & 26288.8 & +0.1 \\
.11923 & 34.9609 & 26222.8 & -0.1 \\
.02404 & 34.8732 & 26157.1 & -0.1 \\
-.07094 & 34.7862 & 26091.8 & -0.2 \\
-.16632 & 34.7000 & 26027.1 & +0.5 \\
-.26131 & 34.6126 & 25961.6 & -0.2 \\
\hline
\end{tabular}

Run No. 3, $\mathrm{CO}_{2}$ not purified, reduced flow

\begin{tabular}{r|r|r|r}
0.12189 & 34.9644 & 26225.4 & 0.0 \\
.02739 & 34.8774 & 26160.2 & +0.1 \\
-.06769 & 34.7899 & 26094.6 & 0.0 \\
-.16297 & 34.7027 & 26029.2 & 0.0 \\
-.25875 & 34.6154 & 25963.7 & 0.0
\end{tabular}

Run No. 4, sublimed $\mathrm{CO}_{2}$, reduced flow

\begin{tabular}{r|r|r|r}
0.20062 & 35.0353 & 26278.7 & -0.4 \\
.00995 & 34.8583 & 26145.9 & +1.8 \\
-.08011 & 34.7705 & 26080.0 & -1.0 \\
-.17460 & 34.6831 & 26014.5 & -1.2 \\
-.27284 & 34.5958 & 25949.0 &
\end{tabular}

Run No. 5, sublimed $\mathrm{CO}_{2}$, normal flow

\begin{tabular}{r|r|r|r}
0.20486 & 35.0398 & 26282.0 & -0.2 \\
.11046 & 34.9526 & 26216.6 & -0.2 \\
.01577 & 34.8654 & 26151.2 & 0.0 \\
-.07942 & 34.7778 & 26085.6 & 0.0 \\
-.17450 & 34.6904 & 26020.0 & 0.0 \\
-.27077 & 34.6022 & 25953.8 & 0.0 \\
.01596 & 34.8658 & 26151.5 & +0.1 \\
.20595 & 35.0414 & 26283.2 & +0.2 \\
\hline
\end{tabular}

* Means of five to ten temperature observations at each pressure.

TABLE 2. Observed values for the vapor pressure of carbon dioxide at $0{ }^{\circ} \mathrm{C}$

\begin{tabular}{|c|c|c|c|c|c|}
\hline $\begin{array}{l}\text { Run } \\
\text { No. }\end{array}$ & $\begin{array}{l}\text { Pres } \\
\text { (bars) }\end{array}$ & $\begin{array}{l}\text { are } \\
\left(\mathrm{mmH}_{\mathrm{g}}\right)\end{array}$ & $\begin{array}{l}\text { Std. dev. of pres. } \\
(\mathrm{mmHg})\end{array}$ & $\begin{array}{c}\text { Slope } \\
\left(\mathrm{mmHg} /{ }^{\circ} \mathrm{C}\right)\end{array}$ & $\begin{array}{l}\text { Std. dev. of slope } \\
\left(\mathrm{mmH} / /^{\circ} \mathrm{C}\right)\end{array}$ \\
\hline 1 & 34.8523 & 26141.4 & 0.24 & 689.7 & 3.1 \\
\hline 2 & 34.8514 & 26140.7 & 0.21 & 687.9 & 0.9 \\
\hline 5 & 34.8510 & 26140.4 & (1).09 & 690.9 & 0.4 \\
\hline Vean & 34.8516 & 26140.8 & & 689.5 & \\
\hline
\end{tabular}

TABLE 3. Test at reduced flow rates

\begin{tabular}{r|r|r|r|r|r}
$\begin{array}{c}\text { Run } \\
\text { No. }\end{array}$ & \multicolumn{2}{|c|}{$\begin{array}{c}\text { Pressure } \\
\text { (bars) } \\
(\mathrm{mmHg})\end{array}$} & $\begin{array}{c}\text { Std. dev. of pres. } \\
(\mathrm{mmHg})\end{array}$ & $\begin{array}{c}\text { Slope } \\
\left(\mathrm{mmHg} /{ }^{\circ} \mathrm{C}\right)\end{array}$ & $\begin{array}{c}\text { Std. dev. of slope } \\
\left(\mathrm{mmHg} /{ }^{\circ} \mathrm{C}\right)\end{array}$ \\
\hline & & & 0.04 & 689.5 & 0.4 \\
4 & 34.8520 & 26141.2 & 1.24 & 701.3 & 5.5 \\
\hline
\end{tabular}

Table 3 shows the effect of reducing the $\mathrm{CO}_{2}$ flow rate by a factor of ten. Run 4 was relatively erratic and gave a low mean pressure, compatible with intermit- tent coverage of the well with liquid. Since operation at this reduced flow rate is not to be recommended, both runs 3 and 4 were excluded from the result to be reported.

These results are compared with those of other authors in table 4. Much of the previous work was reported in $\mathrm{mm} \mathrm{Hg}$ (the conventional $\mathrm{mm} \mathrm{Hg}$ is the pressure corresponding to the height of a fluid of density $13.5951 \mathrm{~g} / \mathrm{cm}^{2}$, under normal gravity, 9.80665 $\left.\mathrm{m} / \mathrm{sec}^{2}\right)$. The value, $26,132.2$ reported by Roebuck and Cram was given in terms of the value 13.5955 for the density of mercury; here it has been adjusted to the conventional $\mathrm{mm} \mathrm{Hg}$. Michels et al., and Greig and Dadson reported the value at the triple point of water; the numbers in parentheses were calculated from the reported value and slope.

It is tempting to interpret the differences between the various measurements as indicating differences in the pressure scales of the laboratories. Thus, O. C. Bridgeman included data from ten piston gages, with calibrations made at the Massachusetts Institute of Technology from 1911 to 1926, and Meyers and Van Dusen included data gathered at the National Bureau of Standards between 1919 and 1931. But a close reading of the latter paper shows that more is involved.

TABLE 4. Determinations of the $\mathrm{CO}$.2 point to date

\begin{tabular}{|c|c|c|c|c|c|}
\hline \multirow{2}{*}{ Investigator } & \multirow{2}{*}{ Year } & \multirow{2}{*}{$\begin{array}{c}\text { Bars } \\
0.00{ }^{\circ} \mathrm{C}\end{array}$} & \multicolumn{2}{|c|}{ Millimeters of mercury } & \multirow{2}{*}{ Reference } \\
\hline & & & $0.00^{\circ} \mathrm{C}$ & $0.01{ }^{\circ} \mathrm{C}$ & \\
\hline Bridgeman & 1927 & 34.8567 & 26.144 .7 & & [1] \\
\hline Meyers and Van Dusen & 1933 & & & & {$[2]$} \\
\hline Equation & & & $26,141.7$ & & \\
\hline MIT measurements & & & 26.141 .2 & & \\
\hline NBS measurements & & 34.8498 & 26.139 .5 & & \\
\hline Roebuck and Cram & 1933 & 34.8411 & $26,133.0$ & & {$[3]$} \\
\hline Vichels, et al. & 1950 & $(34.8467)$ & $(26.137 .2)$ & 26.144 .0 & $|4|$ \\
\hline Edmister, et al. & 1964 & 34.8499 & 26.139 .6 & & {$[5]$} \\
\hline Creig and Dadson & 1966 & $(34.8472)$ & $(26,137.6)$ & 26.144 .5 & $|6|$ \\
\hline This paper & 1966 & 34.8516 & $26,140.8$ & $26,147.7$ & \\
\hline
\end{tabular}

Three values taken from the paper of Meyers and Van Dusen are shown in the table. The first is from an equation which was chosen to represent the vapor pressure of the liquid over the full range from the triple point to the critical point. The form of this equation is largely determined by observations made during 1920 on two samples prepared the previous year. The second was measured during 1927 at MIT on NBS sample No. 1. The numerical value was not stated in the paper, but the point is plotted on the graph in which Meyers and Van Dusen compared the equation and their experimental results. The third value was observed during 1929 at the NBS on the same sample. It will be seen that the measurements at MIT on the NBS and MIT samples differ by twice as much as the measurements by the two laboratories on the NBS sample, and that the difference between the two laboratories was less than the estimated systematic errors $(0.01 \%$ for the NBS) in the pressure measurements. 
The difficulties of realizing a temperature of $0.000{ }^{\circ} \mathrm{C}$ in an ice bath are substantial. The ice point is defined at the temperature of melting pure ice in contact with water which is saturated with air. Pure water is in equilibrium with pure ice at atmospheric pressure and a temperature of $0.003{ }^{\circ} \mathrm{C}$. This temperature difference corresponds to $2.1 \mathrm{~mm}$ of mercury at the $\mathrm{CO}_{2}$ point. Since freshly melted ice is free of air, the conditions of the definition are hard to realize. The investigators both at MIT and the NBS were fully aware of these difficulties and it is probable that their temperatures did not differ by more than $0.0005{ }^{\circ} \mathrm{C}$.

Apparently, at least part of the difference between the values published by the two laboratories must be charged to the preparation of the samples of carbon dioxide. Both laboratories took elaborate precautions to avoid chemical contamination. The gas was obtained by decomposition of sodium bicarbonate, dried with $\mathrm{P}_{2} \mathrm{O}_{5}$, and then sublimed five to eight times. In addition, at the NBS, the liquid was cooled by evaporation several times to obtain the solid. While substantial amounts of chemical contaminants seem unlikely, the possibility of isotope separation cannot be ruled out.

Recent determinations of the $\mathrm{CO}_{2}$ point, including those made in Europe [4,6], are lower than this measurement by an amount which slightly exceeds the sum of the uncertainties estimated by the various authors. This difference may be systematic as between the static and dynamic methods. However, one point with regard to the gas-lubricated piston gage should be mentioned. Carbon dioxide cools substantially on expansion. If this cooling reduces the temperature of the piston significantly, the effective area would be decreased and the apparent pressure increased. Estimates based on the Joule-Thompson coefficient and thermal conductivity of $\mathrm{CO}_{2}$, the rate of leak, and the clearance indicate that this effect would not exceed $0.1 \mathrm{deg}$ in temperature or $2 \mathrm{ppm}$ in the pressure. This point could be verified by operation of the piston gage with helium, which has a positive Joule-Thompson coefficient.

\section{Conclusions}

In the use of the vapor pressure of $\mathrm{CO}_{2}$ as a means of calibration, at least three factors are of comparable importance, i.e., pressure measurement, temperature measurement, and preparation of the sample.

Measurement of the vapor pressure of $\mathrm{CO}_{2}$ by the dynamic method appears to be insensitive to impurities, at least at the level found in commerically available $\mathrm{CO}_{2}$ in gas cylinders. The use of a gas-lubricated piston gage eliminates the need of fluid or diaphragm separators with the associated possible systematic errors.

The authors are indebted to J. L. Cross and his associates who furnished the piston gage and temperature measuring equipment and determined their parameters.

\section{References}

[1] O. C. Bridgeman, A fixed point for the calibration of pressure gages. The vapor pressure of liquid carbon dioxide at $0{ }^{\circ} \mathrm{C}$. J. Amer. Chem. Soc., 49, 1174-1183 (May 1927).

[2] C. H. Meyers and M. S. Van Dusen, The vapor pressure of liquid and solid carbon dioxide, J. Res. NBS 10, 381 (1933) RP538.

[3] J. R. Roebuck and Winston Cram, A multiple column mercury manometer for pressure to 200 atmospheres, Rev. of Sci. Instr., 8, 215 (1937).

[4] A. Michels, et al., The vapor pressure of liquid carbon dioxide, J. Appl. Phys. 16, 501 (1950).

[5] W. C. Edmister, H. G. McMath, and R. C. Lee, Pressure comparisons for dead weight piston gages and vapor pressure of carbon dioxide, Oklahoma State University, unpublished paper (1964).

[6] R. G. P. Greig and R. S. Dadson, The vapour pressure of carbon dioxide at $0.01{ }^{\circ} \mathrm{C}$, Brit. J. Appl. Phys., 17, 1633 (1966).

[7] H. F. Stimson, Precision resistance thermometry and fixed points, precision measurement and calibration, II, Heat and mechanics, NBS Handbook 77, 40 (1964).

[8] E. C. Lloyd and D. P. Johnson, Static and dynamic calibrations of pressure-measuring instruments at the National Bureau of Standards, Automatic and remote control, p. 274 (Proceedings of the First International Congress of the International Federation for Automatic Control, Moscow) (Butterworths, London, 1960).

[9] D. P. Johnson and D. H. Newhall, The piston gage as a precise pressure-measuring instrument, Trans. ASME, 75, 301 (1953).

[10] J. L. Cross, Reduction of Data for piston gage pressure measurements, NBS Mono. 65 (1963).

[11] J. Hilsenrath et al., OMNITAB, a computer program for statistical and numerical analysis, NBS Handbook 101 (1966).

(Paper 72C1-266) 